\title{
EVALUACION FISICOTERMICA Y REOLOGICA DE HARINA Y ALMIDÓN DE PLÁTANO DOMINICO HARTÓN (Musa paradisiaca $\mathrm{ABB}$ )
}

\section{THERMAL AND RHEOLOGICAL EVALUATION OF FLOUR AND STARCH FROM BANANA DOMINICO HARTON (Musa paradisiaca $\mathrm{ABB}$ )}

\author{
Jairo Montoya1, Victor D. Quintero ${ }^{1 *}$ y Juan C. Lucas ${ }^{1}$
}

Recibido para publicación: Enero 6 de 2014 - Aceptado para publicación: Junio 19 de 2014

\begin{abstract}
RESUMEN
El presente trabajo se realizó con la finalidad de evaluar una fuente no convencional de harina y almidón. Se caracterizó fisicoquímicamente mediante análisis proximal, calorimetría diferencial de barrido (DSC), análisis termogravimétrico (TGA); microscopía electrónica de barrido (SEM); difracción de rayos X (XRD) y análisis de viscosidad rápida (RVA). En el análisis proximal la harina arrojó: humedad 7,43\%, proteína 2,57\%, grasa $0,20 \%$, cenizas 2,43\%; mientras que el almidón: humedad $8,7 \%$, proteína $1,53 \%$, grasa $0,12 \%$, cenizas $1,07 \%$, fibra 1,67\%. El análisis de DSC en la harina y almidón presentaron temperaturas de gelatinización y entalpias relativamente bajas $69,3^{\circ} \mathrm{C}$ y $2,02 \mathrm{~J} / \mathrm{g}$ y $54,7^{\circ} \mathrm{C}$ y $2,4 \mathrm{~J} / \mathrm{g}$ respectivamente. El análisis de TGA en la harina y el almidón mostraron temperaturas de descomposición de los compuestos de bajo peso molecular a los $286,1^{\circ} \mathrm{C}$ y $230^{\circ} \mathrm{C}$. Los gránulos de almidón mostraron formas elípticas, con una longitud y diámetros promedio de $39 \mu \mathrm{m}$ y $24 \mu \mathrm{m}$. Los difractogramas de rayos $X$ arrojaron un patrón de difracción tipo C para la harina y para el almidón. La harina y el almidón presentaron, viscosidades de 1132 cP y 2068 cP, con temperaturas de empastamiento de 75,1 y $76,8^{\circ} \mathrm{C}$; una viscosidad final de $1121 \mathrm{cP}$ y $2530 \mathrm{cP}$; Breakdown de 18 y 285 cP; Secback de 107 y 747 cP. La evaluación fisicoquímica y térmica de las harinas y del almidón, presentaron características térmicas atractivas para reducción de costos energéticos en diferentes procesos agroindustriales.
\end{abstract}

Palabras Clave: análisis proximal, propiedades termofísicas, reología.

\begin{abstract}
This work was performed in order to evaluate an unconventional source of flour and starch. It was characterized physicochemically by proximate analysis, differential scanning calorimetry (DSC), thermogravimetric analysis (TGA); scanning electron microscopy (SEM); X-ray diffraction (XRD) analysis and rapid viscosity (RVA). In the proximal analysis, the flour threw: humidity $7.43 \%, 2.57 \%$ protein, $0.20 \%$ fat, $2.43 \%$ ash; while starch: $8.7 \%$
\end{abstract}

${ }^{1}$ Profesores Asistentes, Programa de Ingeniería de Alimentos - Facultad de Ciencias Agroindustriales - Universidad del Quindío - Colombia. *victordumar@uniquindio.edu.co. 
humidity, $1.53 \%$ protein, $0.12 \%$ fat, $1.07 \%$ ash, $1.67 \%$ fiber. DSC analysis of the flour and starch presented gelatinization temperatures and showed relatively low enthalpies $69.3{ }^{\circ} \mathrm{C} 2.02 \mathrm{~J} / \mathrm{g} 54.7{ }^{\circ} \mathrm{C}$ and $2.4 \mathrm{~J} / \mathrm{g}$ respectively. TGA analysis of the flour and starch showed decomposition temperatures of the compounds of low molecular weight at $286.1^{\circ} \mathrm{C}$ and $230{ }^{\circ} \mathrm{C}$. Starch granules showed elliptical shapes, and an average length of 39 microns and 24 microns diameter. X-ray diffractograms yielded a diffraction pattern for type $\mathrm{C}$ for the flour and starch. The flour and starch presented viscosities of $1132 \mathrm{cP}$ and $2068 \mathrm{cP}$, pasting temperatures of 75.1 and $76.8^{\circ} \mathrm{C}$; A final viscosity of $1121 \mathrm{cP}$ and $2530 \mathrm{cP}$; Breakdown of 18 and $285 \mathrm{cP}$; Secback 107 and $747 \mathrm{CP}$. The physicochemical and thermal evaluation of flour and starch, presented attractive thermal characteristics to reduce energy costs in different agro-industrial processes.

Key words: proximate analysis, thermo physical properties, rheology.

\section{INTRODUCCIÓN}

Las plantas de banano y plátano son las hierbas más grandes del mundo, que crecen en abundancia en muchos países en desarrollo. Se considera que es una de las fuentes de energía más importante en la dieta de las personas que viven en regiones tropicales húmedas. Son plantas cultivadas en regiones cálidas y húmedas y dan frutos todo el año (Lassoudière 2007). Es el cultivo de frutas líder en el mundo y en términos de valor económico es el número cinco de los cultivos agrícolas en el comercio mundial. Hay cerca de 100 países productores en zonas tropicales y subtropicales en los 5 continentes. Los productos de banano representan una fuente de alimento esencial y tienen un papel socioeconómico y ecológico importante.

El plátano verde se consume cocido, mientras que el banano de postre maduro se come crudo. El consumo diario per cápita de plátanos es de $30 \mathrm{~g}$ hasta más de $500 \mathrm{~g}$. Aparte de la fruta, otras partes de la planta también se utilizan: el pseudotallo se utiliza para fibras y como flotadores (Musa textilis o abacá) en Filipinas. Las hojas se utilizan para hacer abrigos o techos o como envolturas para cocinar. En Tailandia, las yemas florales de determinadas variedades (Pisang Awak) se utilizan en diversas preparaciones culinarias. Algunas variedades son también consideradas al tener propiedades medicinales (Bakry et al. 2008).

El almidón es la forma principal de almacenamiento de carbono en los plátanos y bananos verdes. Las amilasas permiten la transformación del almidón en azúcares durante la maduración por despolimerización de las cadenas $\alpha$-glucanos, que se rompen por endoenzimas hidrolíticas (Oliveira do Nascimento et al. 2006). El almidón en la fruta verde se convierte en azúcares como sacarosa, glucosa, fructosa y en muy pequeñas cantidades de maltosa y ramnosa, el porcentaje se eleva del 1 o $2 \%$ a casi el $20 \%$ al final de la maduración. El contenido total de sólidos solubles en el banano se aumenta con el desarrollo de la maduración del fruto (Bugaud et al. 2006).

En los últimos treinta años, muchos estudios se han publicado acerca de pulpa de plátano y banano verde, como la producción de harinas de diferentes variedades, sobre algunas de las propiedades estructurales, fisicoquímicas y funcionales del almidón, la digestibilidad y el sabor. Se producen a partir de grandes cantidades de banano rechazado en la industria de exportación. Dichos rechazos consisten en frutas por debajo del grado de calidad y/o 
frutas con defectos de apariencia en la piel y generalmente representa el $20 \%$ de la cosecha. También se han hecho estudios sobre las propiedades nutricionales y no nutricionales, como la harina de plátano, la extracción de almidón y usos. Zhang et al. (2005), analizaron el almidón de plátano y las perspectivas de mejorar el conocimiento de su arquitectura molecular.

El almidón de musáceas aparentemente es tan funcional como el almidón de maíz, con buena aceptabilidad potencial debido a su falta de sabor, siendo relativamente diferentes de los almidones de otras plantas. Hay usos a escala limitada, como un ingrediente de yogures y salsas de tomate, sustitución de la harina de plátano, en ciertas proporciones a la harina de trigo que se utiliza en preparaciones de panadería y pastelería (Juárez et al. 2006). En fideos y tallarines, que es un preparado que contiene almidón de plátano, mostrando una digestibilidad limitada debido a su relativamente alto contenido de almidón resistente y una moderada predicción in vitro del índice glucémico (Osorio et al. 2008).

El almidón y la harina han sido parte fundamental en la dieta del hombre desde la prehistoria, además se le ha dado un gran número de usos industriales. Después de la celulosa, el almidón es probablemente el polisacárido más importante y abundante desde el punto de vista comercial, se encuentra en las semillas de cereales (maíz, trigo, arroz, sorgo), en tubérculos (papa), en raíces (yuca, batata, arrurruz), en semillas de leguminosas (frijoles, lentejas, guisantes), frutas (bananas, manzanas y tomates verdes), troncos (palma sajo) y hojas (tabaco); su concentración varía según el estado de madurez de la fuente, siendo el trigo y el maíz, las más abundantes y utilizadas y sobre las que más estudios existen (Lucas et al. 2010).

En Colombia existen otras alternativas de almidón y harina como el Plátano Dominico Hartón $(A B B)$, que puede ser una opción importante en el mercado de productos procesados y más en el contexto actual, donde el incremento del costo del trigo y el maíz debido a su demanda para la obtención de biocombustible han originado aumento de costos en los productos derivados de estas materias primas.

De acuerdo con lo anterior se hace necesario evaluar fisicoquímica, térmica y reológicamente la harina y el almidón de plátano Dominico Hartón (Musa paradisiaca ABB) con el objetivo de buscar alternativas de uso en la industria alimentaria y no-alimentaria.

\section{MATERIALES Y MÉTODOS}

Se trabajó con la variedad Dominico Hartón $A A B$ cultivada en la finca la Lucia ubicada en el municipio de Armenia - Departamento del Quindío, a una altitud de 1100 msnm, con una temperatura media de $21,9^{\circ} \mathrm{C}$ y una humedad relativa del $85 \%$. El tiempo de cosecha fue de 15 semanas después de la aparición de la bellota y se realizó bajo los conocimientos empíricos del agricultor; su procedencia corresponde a monocultivo y de condiciones fitosanitarias óptimas para las plantas.

Inicialmente el material de estudio fue transportado a los laboratorios de la planta piloto de la Universidad del Quindio, donde fueron pesados y después se les retiró la cascara para pesarlos nuevamente. Los bananos pelados fueron cortados en rodajas y colocados en estufa 
de secado (marca Memmert UL40, Alemania) a $40{ }^{\circ} \mathrm{C}$ durante $48 \mathrm{~h}$, antes de pasarlos por un molino IKA 2870900 MF 10.1, USA. Finalmente se pasaron por filtro con membrana de tamaño de poro de $100 \mu \mathrm{m}$, con el fin de obtener la harina (Lucas et al. 2013). Para la extracción del almidón se utilizó el método tradicional, consistente en adicionar agua a las rodajas de banana en relación 1:1, antes de licuar 6.000 r.p.m. durante 1 min y pasó a través de una malla de $100 \mu \mathrm{m}$, con adición de abundante agua destilada. La mezcla fue centrifugada a 10.000 r.p.m. durante $1 \mathrm{~min}$ a $25{ }^{\circ} \mathrm{C}$. El precipitado se filtró a través de una membrana con tamaño de poro de $100 \mu \mathrm{m}$ y el filtrado que contenía el almidón se secó en estufa de recirculación (marca Memmert UL40, Alemania) a $40{ }^{\circ} \mathrm{C}$ por 48 h (Dufour et al. 2008).

\section{Análisis Proximal}

El contenido de humedad se determinó por método oficial AOAC 925.10 (2005), el contenido de ceniza se realizó siguiendo el método oficial AOAC 923.03 (2005), la fibra para la harina se determinó por Método oficial AOAC 991.42 (2005) y para el almidón se utilizó el Método oficial AOAC 985.29 (2005), la grasa se cuantificó por el Método Oficial AOAC 922.06 (2005) y la cantidad de proteínas por el método oficial AOAC 960.52 (2005).

\section{Caracterización Física y Térmica}

\section{Calorimetría Diferencial de Barrido (DSC)}

La determinación de la temperatura $\left[\mathrm{Tp}\left({ }^{\circ} \mathrm{C}\right)\right]$ y la entalpía de gelatinización $[\Delta \mathrm{Hp}(\mathrm{J} / \mathrm{g})]$ de la harina y del almidón se llevó a cabo en un equipo TA Instruments DSC-Q100, en muestras de (10,00 $\pm 0,50)$ mg con un contenido de humedad del $80 \%$, para una velocidad de calentamiento de $5{ }^{\circ} \mathrm{C} / \mathrm{min}$, desde temperatura ambiente hasta
$100{ }^{\circ} \mathrm{C}$, en atmósfera de Nitrógeno. (Pineda et al. 2011).

\section{Análisis Termogravimétrico (TGA)}

Este análisis se realizó en un equipo TA Instruments TGA Q500, en presencia de una atmósfera de nitrógeno para un rango desde la temperatura ambiente hasta $800{ }^{\circ} \mathrm{C}$, con una velocidad de calentamiento de $5{ }^{\circ} \mathrm{C} / \mathrm{min}$ en muestras de $6 \pm 0,50 \mathrm{mg}$ (Pineda et al. 2011).

\section{Difracción de Rayos $X$}

Las muestras fueron reducidas a un polvo fino y pasados a través de una malla de $150 \mu \mathrm{m}$, posterior a esto se empacaron densamente dentro de una charola de aluminio; los patrones de difracción de rayos $X$ se obtuvieron usando un difractometro Bruker D8 advance, con una línea de radiación $\mathrm{Cu} K \alpha(\mathrm{l}=1,55418 \AA$ \&), con una diferencia de potencial de $30 \mathrm{kV}$ y una densidad de corriente de $20 \mathrm{~mA}$. Las muestras se colocaron en el equipo con un paso angular de 0,050 entre 5 y 40 grados (20) y un tiempo de conteo por paso angular de 15 segundos. El material se colocó en un portamuestra de aluminio de área de $30 \mathrm{~mm}$ por $30 \mathrm{~mm}$ a temperatura ambiente y baja humedad. (RojasMolina et al. 2007).

\section{Microscopía electrónica de barrido (SEM)} La morfología de la harina y el almidón se realizó con un microscopio electrónico de barrido (Marca JEOL, Modelo JSM-6060LV, Japón) con alto vacío y una resolución de $5 \mathrm{~nm}$ en modo de alta tensión. Los análisis fueron realizados a $20 \mathrm{kV}$ de tensión de aceleración de electrones y 12 - 20 Pa de presión de la cámara en las muestras, obteniendo imágenes en las superficies de fractura con la señal de electrones secundarios (Lucas et al. 2010). 


\section{Análisis de viscosidad rápida (RVA)}

Se prepararon dos clases de pastas acuosas, la primera solución contenía $8 \%$ de harina con un inhibidor de $\alpha$-amilasa $\left(\mathrm{AgNO}_{3}\right.$; 0,002 $\mathrm{mol} / \mathrm{L}$ ) y la segunda solución al 7\% de almidón sin inhibidor. El equipo utilizado fue un viscoanalizador rápido RVA-4 (Newport, Australia). Se calentó la solución con agitación constante desde 50 hasta $90{ }^{\circ} \mathrm{C}$ con una velocidad de calentamiento de $6{ }^{\circ} \mathrm{C} / \mathrm{min}$, seguido de esto se mantuvo la temperatura de $90{ }^{\circ} \mathrm{C}$ durante 5 minutos y finalmente se enfrió hasta $50{ }^{\circ} \mathrm{C}$ a una tasa de $6{ }^{\circ} \mathrm{C} / \mathrm{min}$. (Lucas et al. 2010).

Todos los procedimientos se llevaron a cabo por triplicado y se utilizó un análisis de varianza unilateral al 95\% de confiabilidad para el procesamiento de los datos obtenidos.

\section{RESULTADOS Y DISCUSIÓN}

\section{Rendimiento en la obtención de harina}

Para el plátano Dominico Hartón en estado inmaduro, se obtuvo el $36 \%$ de cascara y $64 \%$ pulpa. El rendimiento en la obtención de harina con respecto al plátano con cascara fue $16,5 \%$ y con respecto a la pulpa húmeda fue de $25,7 \%$. Estos resultados son similares con otros estudios, en los cuales han evaluado el rendimiento en la obtención de harina de plátano. Se encontró que el porcentaje de pulpa para Dominico Hartón, Pelipita, Cachaco y Guineo fueron 26,5; 23,3; 18,4 y 16,4 respectivamente. Para el porcentaje de cascara 14,$3 ; 13,0 ; 16,6$ y 15,3 para los anteriores materiales o clones (Morales et al. 1998; Pelissari et al. 2013; Nwokocha et al. 2009 y Alkarkhi et al. 2011).
Rendimiento en la extracción de almidón Del peso total de la pulpa se obtuvieron 470 gramos de almidón, que representan un $8,87 \%$ del peso de la pulpa y el $30,7 \%$ con respecto del total de almidón presente en la pulpa de plátano.

Comparando los resultados con los reportados por Flores (2004), donde obtuvieron rendimientos entre $59,2 \%$ y $60,7 \%$ de pulpa, con una recuperación entre el 63 y $71 \%$ del almidón total de la extracción, se infiere que se podría haber optimizado el método de extracción del almidón.

\section{Caracterización química en harinas y almidones}

Para la harina (Tabla 1) se encontró que ésta presentó un contenido de humedad de 7,43\%, contenido que es mayor a 3,9\% y $6,17 \%$ obtenido por Da Mota et al. (2000) para plátanos de diferentes variedades. Se evidencio un contenido de humedad similar con la harina de yuca; aunque se observa una diferencia de $4,17 \%$ con respecto al contenido de humedad de la harina de maíz. El contenido de humedad registrado en la harina de plátano Dominico Hartón se encuentra dentro de los parámetros de calidad establecidos por la Norma Técnica Colombiana para harina de trigo (NTC 267).

Al comparar los resultados de cenizas obtenidos en la harina de plátano, se encontró concordancia con lo reportado por otros autores Da Mota et al. (2000). También se evidencio que el contenido de ceniza de la harina de plátano presentó cantidades similares a la harina de maíz y a la harina de yuca.

La harina de plátano presentó un valor de 2,57\% en proteína, valor que se encuentra por debajo 
Tabla 1. Análisis proximal de diferentes fuentes de harina y almidón.

\begin{tabular}{lccccccc}
\hline Producto Variable & $\begin{array}{c}\text { 1Harina de } \\
\text { plátano }\end{array}$ & $\begin{array}{c}\text { Harina de } \\
\text { maíz }\end{array}$ & $\begin{array}{c}\text { Harina de } \\
\text { yuca }\end{array}$ & $\begin{array}{c}* 2 \text { Harina de } \\
\text { plátano }\end{array}$ & $\begin{array}{c}\text { Almidón de } \\
\text { yuca }\end{array}$ & $\begin{array}{c}{ }^{3} \text { Almidón de } \\
\text { plátano }\end{array}$ & $\begin{array}{c}\text { Almidón } \\
\text { de plátano }\end{array}$ \\
\hline Humedad (\%) & 9,45 & 11,6 & 8,5 & $7,43 \pm 0,45$ & 8,47 & 9,26 & $8,7 \pm 0,04$ \\
Ceniza (\%) & 2,10 & 3,8 & 5,2 & $2,43 \pm 0,11$ & 0,15 & 0,12 & $1,07 \pm 0,04$ \\
Proteína (\%) & 3,32 & 11 & 4,4 & $2,57 \pm 0,006$ & 0,60 & 0,62 & $1,53 \pm 0,01$ \\
Lípidos (\%) & 2,45 & 7,7 & 0,7 & $0,20 \pm 0,006$ & 0,31 & 0,14 & $0,12 \pm 0,001$ \\
Fibra cruda (\%) & 1,65 & 6,4 & 5,2 & ND & 0,04 & 0,14 & $1,67 \pm 0,005$ \\
\hline
\end{tabular}

${ }^{*}$ correspondientes a esta investigación. ${ }^{1}$ Harina de plátano variedad M. paradisiaca. ${ }^{2}$ Harina de plátano variedad Dominico Hartón. ${ }^{3}$ Almidón de plátano nativo. ND: No Determinado. Datos tomados y adaptados de Soto Azurdy (2010) (Musa Paradisiaca) y Cardona et al. (2001) (Harinas de maíz y yuca).

del contenido de proteína en la harina de maíz y de yuca, ademas el contenido de grasa en la harina de plátano fue de $0,20 \%$. Con respecto a la harina de yuca, ésta presenta valores similares, pero se evidencian diferencias con la harina de maíz. Es importante resaltar que los contenidos de proteína, grasa y minerales son aceptables para desarrollar productos con un buen aporte nutricional; la harina de plátano podría ser usada para la elaboración de harinas combinadas, sopas, coladas y en la fabricación de galletas.

En relación a las características del almidón, el contenido de humedad para dominico hartón fue de $8,7 \%$. Resultado similar al contenido de humedad de 9,26 reportado por Olayide et al. (2008), para almidón de plátano nativo. También se evidenciaron similitudes con otras fuentes de almidón como yuca y papa con $8,50 \%$ y ñame que varía entre 8,66 y $10,22 \%$ (Alvis et al. 2008).

En el almidón se encontró un contenido de proteína menor que el obtenido por Bello et al. (1998) quienes reportaron 2,03\%, pero fue mayor al determinado por Rivas et al. (2008) con 0,8\% y por García et al. (2011) con $1,06 \%$ para almidón de plátano. En cuanto al contenido de extracto etéreo se obtuvo un valor de $0,12 \%$, el cual fue menor al obtenido por Bello et al. (1998), con el 2,46\% y al determinado por García et al. (2011), con 0,35\%, en almidón de plátano. Se evidenció que el contenido de almidón del plátano y yuca no presenta grandes diferencias $0,12 \%$ y $0,31 \%$ respectivamente.

Los almidones de papa, yuca y plátano Dominico Hartón contienen muy poca cantidad de lípidos, comparados con los almidones de cereales (maíz y arroz), los cuales poseen respectivamente 0,6 y 0,8\%. Esta composición favorece al almidón de plátano, ya que estos lípidos forman un complejo con la amilosa, la cual tiende a reprimir el hinchamiento y la solubilización de los gránulos de almidón; por esta razón se necesitan temperaturas altas $\left(>125^{\circ} \mathrm{C}\right)$ para romper la estructura amilosalípido y solubilizar la fracción de amilosa, la mayor parte de estos lípidos son lisofosfolípidos; es decir una cadena de ácido graso esterificada con ácido fosfórico. La presencia de sustancias grasas puede crear 
problemas por la tendencia a la rancidez durante el almacenamiento (Hurtado 1997).

El contenido de cenizas fue de 1,07\%, mayor al reportado para almidón de plátano nativo y para el almidón de yuca. El contenido de fibra fue de 1,67\%, mayor a lo reportado (Alvis et al. 2008), para almidones de otras fuentes como papa $(0,05 \%)$ y yuca que varía entre 0,04 y 0,05\%.

\section{Caracterización térmica para harina y almidón Calorimetría diferencial de barrido de harina.}

En la figura $1 \mathrm{~A}$, se presentan los resultados del termograma (DSC) y datos arrojados en el análisis DSC de la harina; donde se evidencia una reacción endotérmica, la cual ocurre cuando el almidón se calienta en un exceso de agua (Donovan 1979).

El rango de temperatura y la localización de dicha reacción suceden independientes de las condiciones del exceso de contenido acuoso, pero sí depende de la fuente botánica de donde proceda el almidón. La harina de plátano presentó una temperatura de inicio de gelatinización $\left(\mathrm{T}_{\mathrm{o}}\right) \operatorname{de} 69,9^{\circ} \mathrm{C}$, evidenciando que la temperatura pico $\left(T_{p}\right)$ que es la temperatura donde se registran los valores más altos de absorción de calor, fue de $73,8{ }^{\circ} \mathrm{C}$. La entalpía de gelatinización $H_{p}$ es la energía absorbida en el proceso, su valor fue de 2,015 J/g y la temperatura final del proceso $\mathrm{T}_{\mathrm{e}}$ fue de $81,6^{\circ} \mathrm{C}$.

Estas temperaturas son dependientes del contenido acuoso, de forma que disminuyen a medida que se incrementa la cantidad de agua, ya que actúa como un plastificante (Slade y Levine 1988). La transición observada corresponde al proceso de fusión de las dobles hélices de la amilopectina y a la perdida de cristalinidad (Cooke y Gidley 1992).

Teniendo en cuenta que los análisis de DSC se realizaron con un $80 \%$ de humedad, los resultados de las curvas de temperatura de gelatinización para la harina de plátano Dominico Hartón, concuerdan con estudios previos de harina de maíz con temperaturas que varían entre 67,3 y $73,2{ }^{\circ} \mathrm{C}$ con $75 \%$ de humedad, los cuales indican que para altos porcentajes de humedad la temperatura de gelatinización disminuye (Pineda et al. 2011). También coincide con temperaturas de gelatinización de harina cruda de yuca de 63,35 ${ }^{\circ} \mathrm{C}$ (Rodríguez et al. 2006).

\section{Calorimetría diferencial de barrido de almidón} La temperatura de inicio de gelatinización para el almidón de plátano Dominico Hartón fue de $54,74{ }^{\circ} \mathrm{C}$ (Figura 1B), se evidencia una reacción endotérmica propia de los almidones cuando son sometidos a un proceso hidrotérmico. La transición observada corresponde al proceso de fusión de las dobles hélices de la amilopectina y la perdida de cristalinidad (Cooke y Gidley 1992).

El almidón de plátano gelatiniza en un rango de temperatura similar a los almidones procedentes de cereales ejemplos: trigo 58-64 ${ }^{\circ} \mathrm{C}$ (Taggart 2004), trigo 57,6-59,4 ${ }^{\circ} \mathrm{C}$ (Vansteelandt y Delcour 1999) aunque la temperatura de gelatinización de almidón de plátano en el presente estudio, estuvo por debajo de lo reportado por Dufour et al. (2009) con $67,7^{\circ} \mathrm{C} \pm 2,2$ para esta misma variedad de plátano. También se presenta diferencias con respecto a la temperatura de gelatinización de almidón de maíz normal y plátano reportado por Espinosa (2008). 
Las diferencias en las temperaturas de gelatinización dependen en gran medida de las condiciones genéticas de los frutos, las condiciones climáticas del cultivo y de las semanas de cosecha. La temperatura final $\left(\mathrm{T}_{\mathrm{e}}\right)$ registrada fue de $91,74{ }^{\circ} \mathrm{C}$, se evidenció que la temperatura de pico $\left(\mathrm{T}_{\mathrm{p}}\right)$ para el almidón de plátano fue de $72{ }^{\circ} \mathrm{C}$.

La entalpía de este proceso fue 2,291 J/g. De acuerdo a los resultados se puede inicar que el almidón de plátano evaluado en el presente estudio, es un almidón fácil de cocinar y requiere menor consumo de energía durante su cocción.

El principal cambio que ocurre en el proceso de gelatinización es el cambio de una forma semicristalina que no es digerible, a una forma eventualmente amorfa y digerible (Tester 1999).

A

DSC Harina Plátano

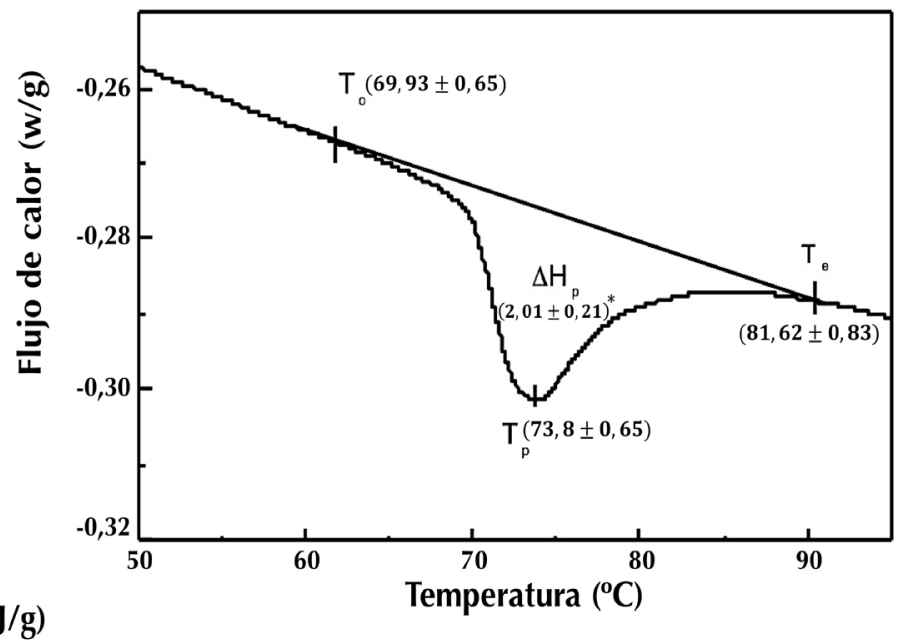

Figura 1A. Termograma DSC de la harina de plátano Dominico Hartón.

B

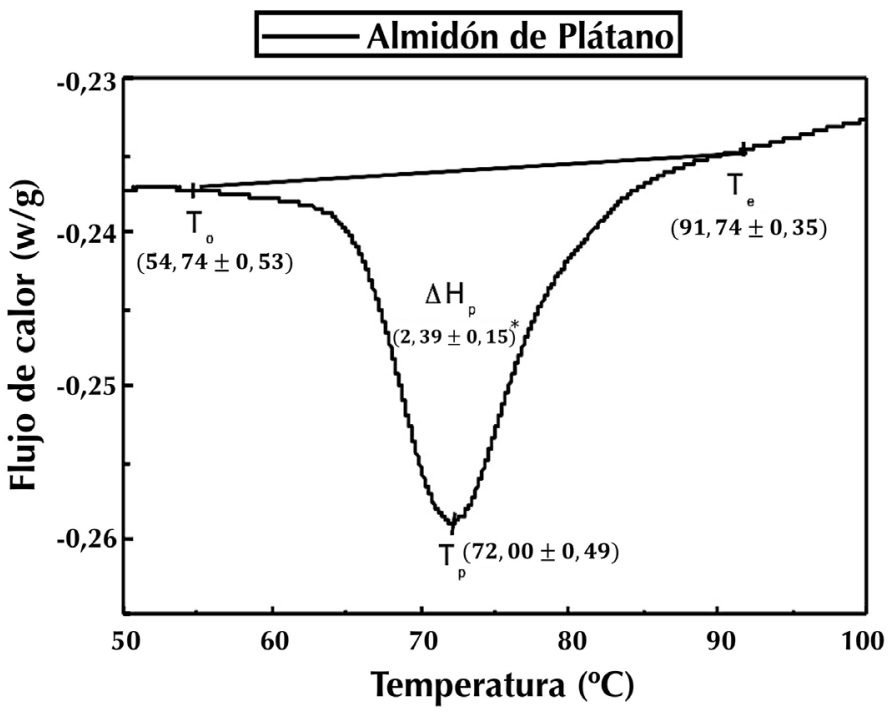

$*(\mathrm{~J} / \mathrm{g})$

Figura 1B. Termograma DSC del almidón de plátano Dominico Hartón. 
Cuando el almidón es hidratado y calentado, se observan cambios químicos, de textura y estructurales los cuales influyen de manera considerable en la calidad del producto final cuando este es incorporado, por ejemplo en la fabricación de pan y tortillas.

De acuerdo a los resultados obtenidos en la prueba de DSC, la harina de plátano mostró un bajo gasto de energía representado como calor, lo cual haría atractivo el producto para reducción de costos energéticos en la elaboración de productos a base de harina.

La temperatura de gelatinización de la harina es más alta con respecto a la temperatura de gelatinización del almidón, debido a los componentes de la harina como: proteínas, lípidos, grasa y minerales, aunque el almidón, también presenta otros componentes, estos se encuentran en menor cantidad.

\section{Análisis termogravimétrico para harina y almidón}

Harina. Para las muestras de harina de plátano se realizó un análisis termogravimétrico (Figura $2 \mathrm{~A}$ y $2 \mathrm{~B}$ ), en el cual se registraron las pérdidas de peso de la muestra sometida a procesos de cambios fuertes de temperatura, debidas a la descomposición, oxidación o deshidratación. En la figura $2 \mathrm{~A}$, se muestran el termograma junto con su derivada de pérdida de peso (línea punteada azul); donde se pueden observar 3 zonas, en las cuales se registró el porcentaje de pérdida de peso y la cantidad de peso en mg que perdió la muestra y en la figura 2B, se aprecia la temperatura aproximada a la que fue registrada la pérdida de peso.

La zona 1 corresponde a la pérdida de masa debida a la humedad presente en la muestra; el porcentaje de agua fue de 9,52\%, que corresponde a un peso de $0,535 \mathrm{mg}$ del total de la muestra, está perdida de peso se registró entre los $100{ }^{\circ} \mathrm{C}$ y $200{ }^{\circ} \mathrm{C}$, teniendo su mayor pico a los $150{ }^{\circ} \mathrm{C}$ aproximadamente (Figura 2B).

La zona 2, es la zona de mayor pérdida de masa en peso con 3,03 mg y corresponde al 53,88\% de la masa total de la muestra, basándose en la composición química de la harina de plátano, este porcentaje corresponde a componentes de bajo peso molecular, carbohidratos y a la cantidad total de almidón presente en la muestra (Alfaro et al. 2004). El rango de temperatura de degradación en esta etapa empieza en $200{ }^{\circ} \mathrm{C}$ y termina en $380^{\circ} \mathrm{C}$ aproximadamente.

La muestra se degrada rápidamente en esta zona, lo cual puede observarse en la curva de la derivada (en color azul), donde la velocidad de cambio (\%/min) toma su valor máximo, en una temperatura de $286,09{ }^{\circ} \mathrm{C}$.

Resultados que evidencian que la harina de plátano contiene altos niveles de almidón y carbohidratos, basándose en los porcentajes de pérdida de peso en la zona 2 .

En la zona 3, se evidenció un rango de temperaturas entre $375{ }^{\circ} \mathrm{C}$ a $580{ }^{\circ} \mathrm{C}$ con un pico máximo de temperatura en $478,37{ }^{\circ} \mathrm{C}$ (Figura 2A y 2B). En estas temperaturas se pueden descomponer polisacáridos de alto peso molecular como proteínas, lípidos entre otros compuestos orgánicos. En este punto la harina presentó una pérdida de peso de $31,97 \%$ corresponde a 1,197 mg. El porcentaje de residuos presentados en el termograma es de 3,548\% corresponde a 0,1995 mg.

Este valor corresponde a la concentración de minerales de la harina de plátano. 
A

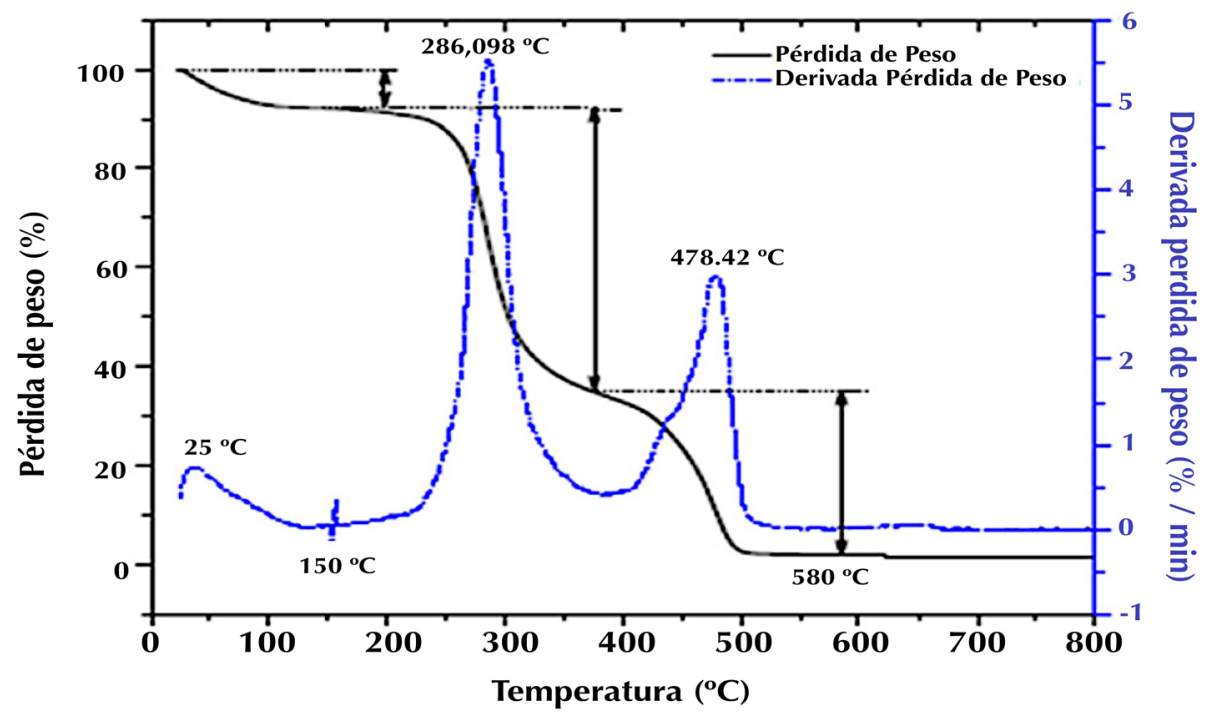

B

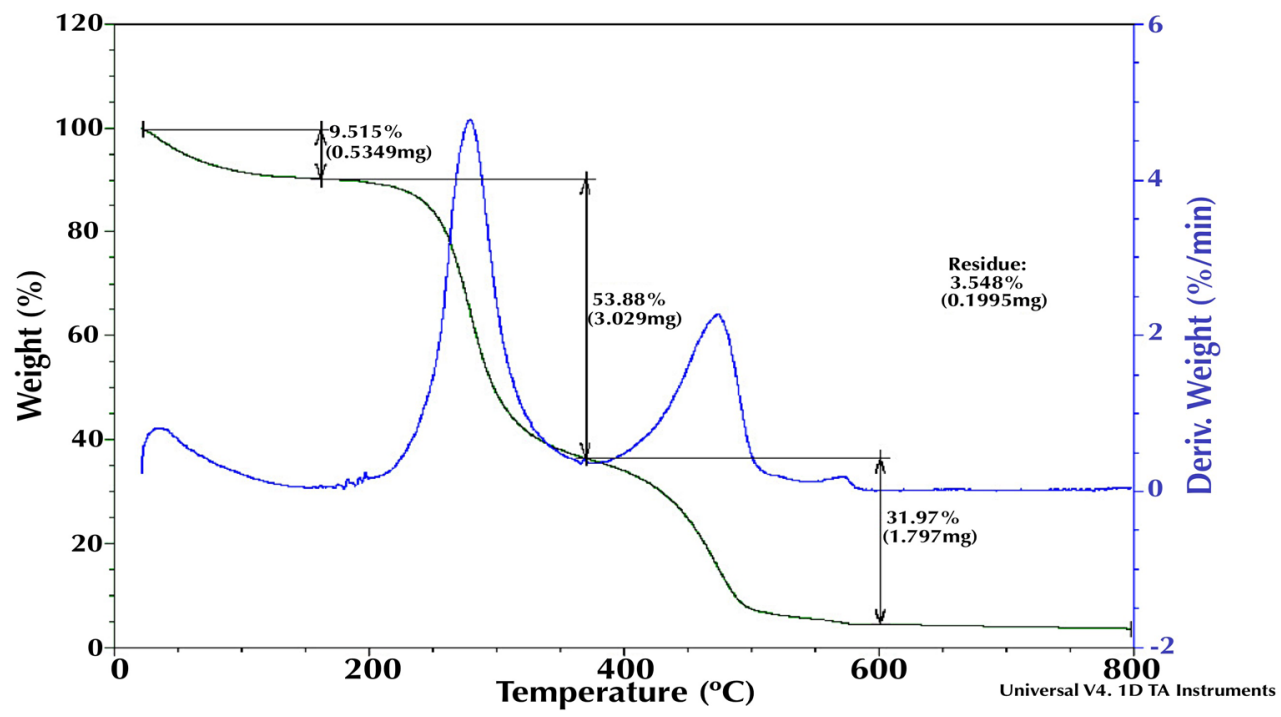

Figura 2A y 2B. Pérdida de peso de la harina de Plátano (TGA).

Almidón. En la figura $3 \mathrm{~A}$ y $3 \mathrm{~B}$, se observan tres zonas importantes donde se representan las pérdidas de peso más pronunciadas. Las gráficas muestran el porcentaje de pérdida de peso, la cantidad de peso en mg que perdió la muestra y la temperatura aproximada a la que fue registrada la pérdida de peso.

La zona 1, corresponde a la pérdida de masa debida a la humedad presente en la muestra.
El porcentaje de agua fue de 11,46\% que corresponde a un peso de 0,54 mg de total de la muestra, esta disminución empieza desde los $100{ }^{\circ} \mathrm{C}$ hasta los $230^{\circ} \mathrm{C}$ aproximadamente, presentando su mayor pico de temperatura a $\operatorname{los} 200,9^{\circ} \mathrm{C}$.

La zona 2, es de mayor pérdida de masa con un porcentaje de $69,7 \%$, corresponde a un peso de 3,285 mg del total de la muestra, a estas temperaturas se descomponen carbohidratos 
y otros elementos de bajo peso molecular; teniendo en cuenta la composición de almidón de plátano este porcentaje de pérdida equivale al almidón total presente en la muestra. La degradación se realizó en el intervalo de temperatura de $230{ }^{\circ} \mathrm{C}$ y $387,45{ }^{\circ} \mathrm{C}$. La velocidad de cambio (\%/min), en esta etapa de descomposición, presenta su valor máximo en $305,3{ }^{\circ} \mathrm{C}$, como lo indica el pico en la curva derivada.

Para la zona 3, se evidencia la descomposición del $18 \%$ que corresponde a $0,85 \mathrm{mg}$ en peso del total de la muestra, con rangos de temperatura desde $390{ }^{\circ} \mathrm{C}$ hasta $548{ }^{\circ} \mathrm{C}$. Esta descomposición es asociada a polisacáridos que tiene un alto peso molecular entre los que se encuentran los residuos proteicos y lípidos. La velocidad de cambio (\%/min), en esta etapa de descomposición, presenta su valor máximo en $508,04{ }^{\circ} \mathrm{C}$.

El residuo de muestra que queda tras las tres descomposiciones, es asociado a la cantidad de minerales presentes en el almidón. Para el plátano Dominico Hartón el residuo

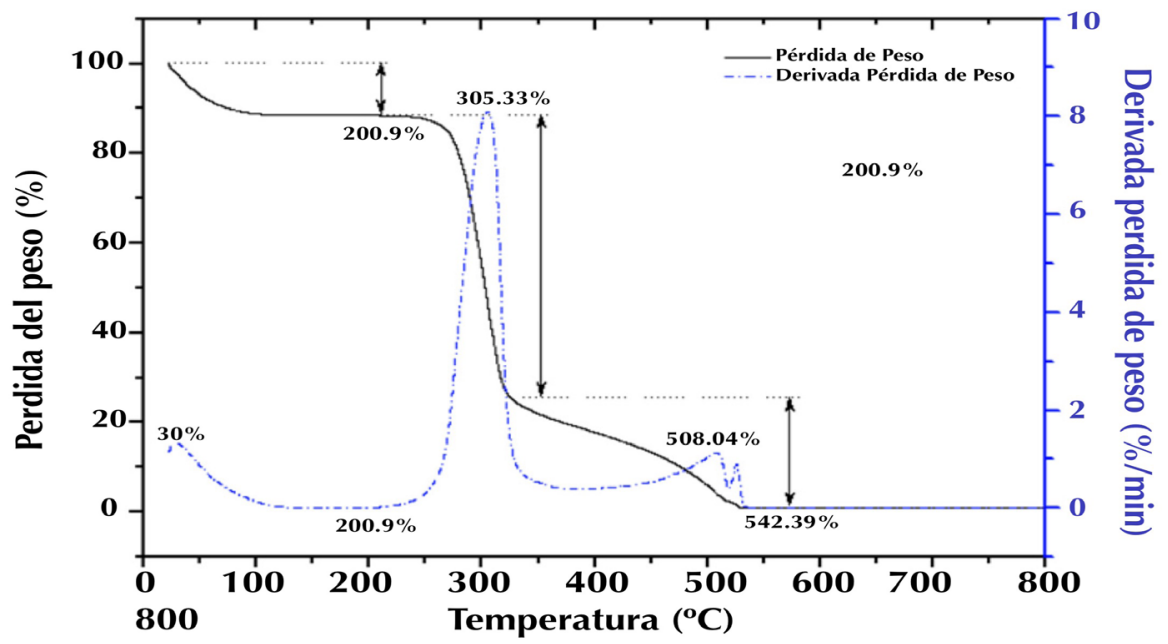

A

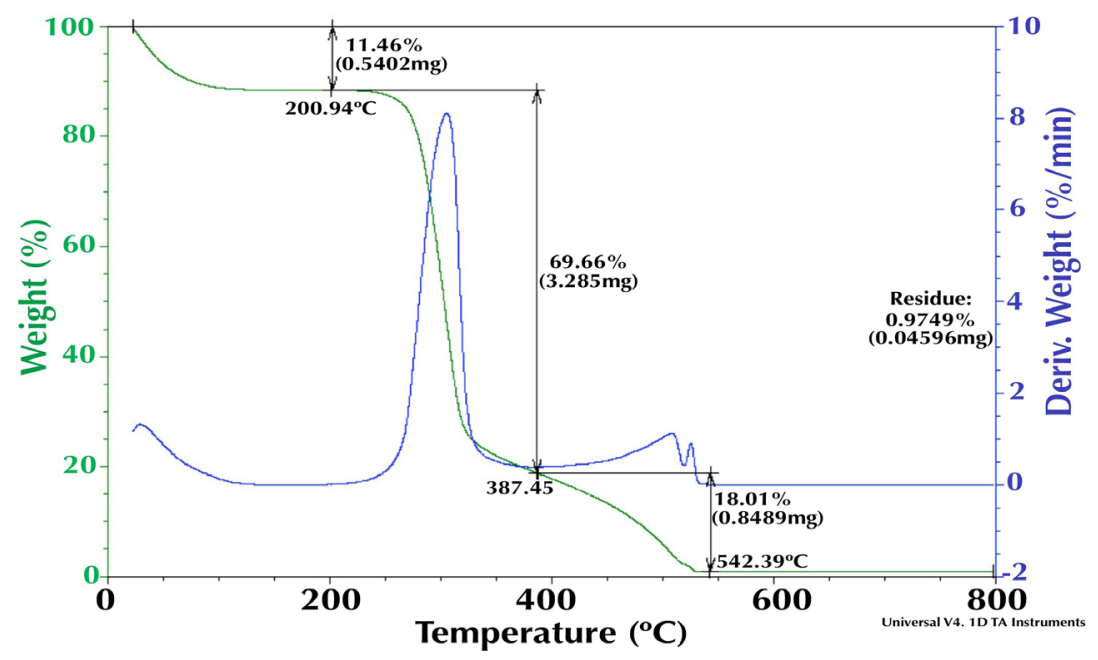

B

Figura 3A y 3B. Pérdida de peso del Almidón de Plátano (TGA). 
corresponde a un $0,97 \%$, que equivale al 0,096 mg en peso del total de la muestra.

Los resultados TGA indican que el almidón de plátano es térmicamente estable a temperaturas inferiores a $200{ }^{\circ} \mathrm{C}$ donde inicia el proceso de degradación térmica.

En la figura 3B, se presenta la velocidad de pérdida de las muestras de harina $y$ almidón a razón de 5,5\%min ${ }^{-1}$ y $8,2 \% \mathrm{~min}^{-1}$, respectivamente. La harina de plátano se descompone de forma más lenta con respecto al almidón de plátano. Lo anterior debido a que la harina posee mayor cantidad de componentes de bajo peso molecular a diferencia del almidón.

La harina también presenta una considerable velocidad de pérdida con 3\%/min, donde elimina componentes de alto peso molecular de proteínas y lípidos.

\section{Caracterización física}

Difracción de rayos $X$ para la harina y almidón de plátano Dominico Hartón. Cuando se irradian cristales con rayos $X$, éstos se separan produciendo un patrón de su estructura cristalina; de acuerdo a la evaluación hecha por difracción de rayos $X$, la estructura del almidón y harina de plátano Dominico Hartón, presentaron un patrón de difracción tipo $\mathrm{C}$, el cual es una mezcla entre los polimorfismos $A$ y B.

La harina y el almidón de plátano presentaron patrones similares (Figura 4A y 4B). La harina registro picos en los ángulos $2 \theta=12,15,17$, 23 (Figura 4A), mientras que el almidón de plátano, presento picos en los ángulos $2 \theta=$ 12, 15, 17, 23, y 26 (Figura 4B).

Este patrón de rayos $X$ encontrado para harina $y$ almidón de plátano coinciden con lo reportado por otros autores (Millán et al. 2005), también determinaron un patrón tipo $\mathrm{C}$ para el almidón Nativo de Musa Paradisiaca.

Otros estudios han reportado patrones de difracción tipo A para almidón de plátano macho y criollo (Bello et al. 2000) y Faisant et al. (1995) reportó patrones de difracción tipo B para almidón de plátano.

El nivel de cristalinidad puede ser importante cuando los productos a base de almidón o con

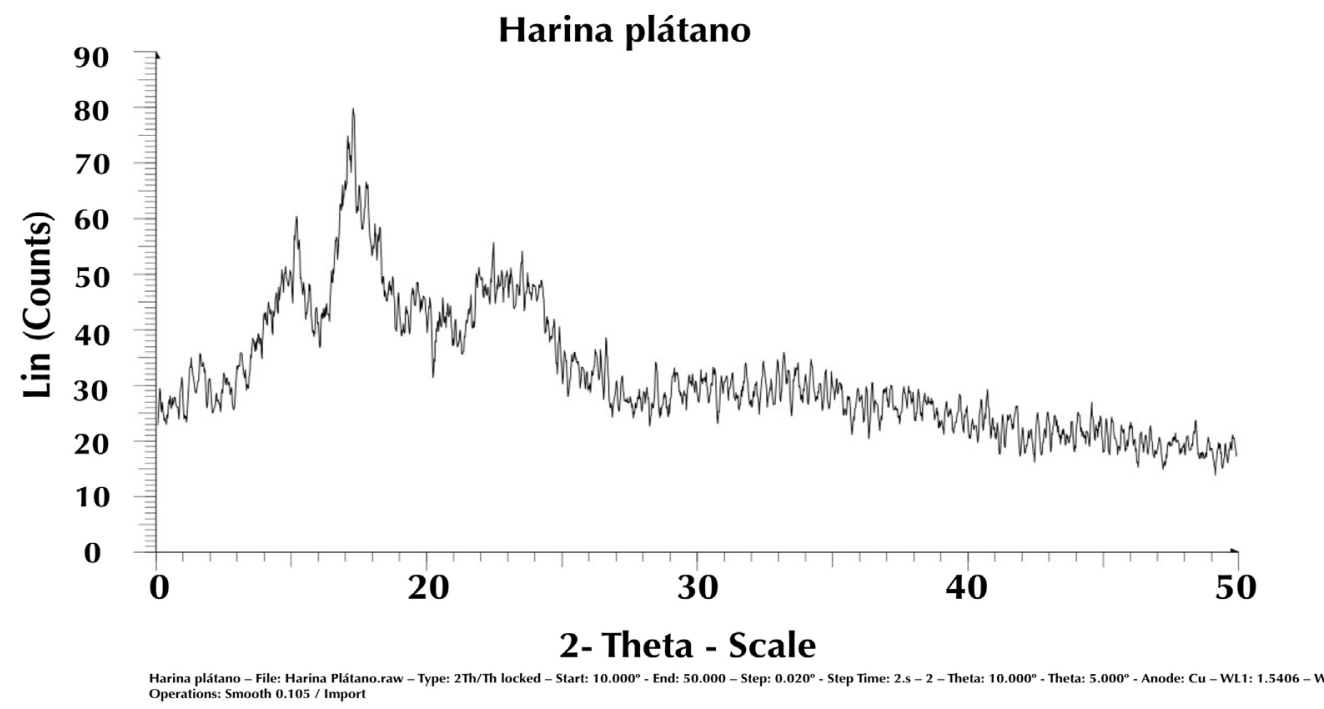

Figura 4A. Difractograma para Harina y Almidón de Plátano. 


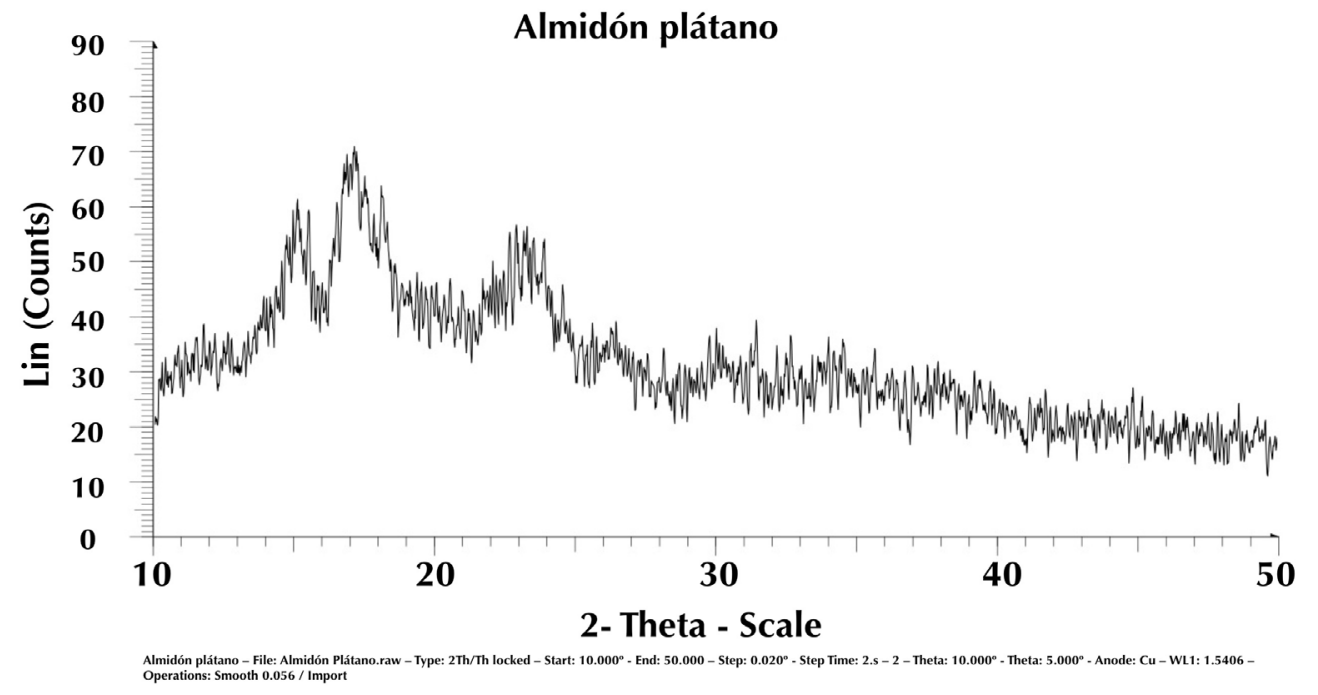

Figura 4B. Difractograma para Harina y Almidón de Plátano.

alto contenido de este son almecanados, ya que durante el almacenamiento se presenta el fenomeno de retrogradación del almidón, que modifica las propiedades de textura y nutricionales de dichos productos. Los almidones de maíz con mayor cristalinidad pueden retrogradar a mayor velocidad o producir estructuras que son resistantes a la hidrolisis por las enzimas digestivas (Amaga 2005).

La difracción de rayos $\mathrm{X}$ tipo $\mathrm{C}$ como la obtenida en el almidón de plátano, se encuentra relacionada con una mayor proporción de cadenas largas de amilopectina; debido al arreglo de estas cadenas en una estructura cristalina, la hidrolisis enzimatica de este tipo de almidón se ve disminuida, esta característica del almidon de platano puede ser utilizada para la producción de almidón resistente (Aparicio 2007).

Microscopía electrónica de barrido de almidón de plátano Dominico Hartón.

Esta técnica se utiliza para la observación y análisis de superficies suministrando información de relieve, textura, tamaño y forma del grano de muestras biológicas y minerales. Para determinar la morfología y el tamaño de los gránulos de almidón de plátano, se halló el valor promedio y desviación estándar del tamaño del granulo de almidón de acuerdo a su diámetro máximo y mínimo, así como las características de superficie y forma del granulo.

En el microscopio de exploración electrónica SEM los electrones inciden desde arriba sobre la preparación, por ello la muestra puede ser de cualquier tamaño. El tamaño del granulo de almidón es un parámetro importante que afecta las características funcionales y fisicoquímicas; se ha reportado que los gránulos muy pequeños pueden absorber una mayor cantidad de agua, en comparación de los gránulos grandes, debido a una mayor área de contacto (Paredes et al. 1989), mientras más pequeños son los gránulos, mayor es su digestibilidad (Tian et al. 1991).

Se puede observar que los gránulos de almidón de plátano Dominico Hartón presentan formas 
redondeadas para los gránulos pequeños y forma elíptica para los gránulos de mayor tamaño. Se han reportado formas similares por otros autores (Olayide et al. 2002). Se encontraron tamaños variables, su longitud se encontró en un rango desde $6 \mu \mathrm{m}$ hasta $53 \mu \mathrm{m}$ con un promedio de $39 \mu \mathrm{m}$; el rango obtenido con respecto al diámetro fue de $7 \mu \mathrm{m}$ hasta $35 \mu \mathrm{m}$ y un promedio de $24 \mu \mathrm{m}$.

Bello et al. (2000), reporto un rango de tamaño de $10 \mu \mathrm{m}$ hasta $50 \mu \mathrm{m}$ y forma irregular para la almidón de origen botánico, mientras que Guilbot y Mercier (1985), reportaron rangos de tamaño de $10 \mu \mathrm{m}$ hasta $40 \mu \mathrm{m}$ y con forma elipsoidal en almidón de plátano.

El almidón de plátano dominico hartón tiene gránulos grandes, comparables a los de almidones de raíces y tubérculos, los cuales son más grandes que los almidones de semillas o cereales (Whistler y BeMiller 1997) y algunos gránulos de papa pueden medir hasta $100 \mu \mathrm{m}$ en su eje mayor. El tamaño promedio de un gránulo de almidón de maíz es de $15 \mu \mathrm{m}$.

\section{Caracterización funcional}

El viscoamilograma permite evaluar la temperatura de inicio de hinchamiento de los gránulos de almidón (temperatura a la cual se puede observar un incremento de la viscosidad), esta temperatura Ilamada temperatura de empastamiento, presentó un valor de $75,1^{\circ} \mathrm{C}$, en un tiempo de calentamiento de 4,17 min (Tabla 2).

\section{Análisis de la curva de empastamiento}

Harina. La viscosidad máxima alcanzada fue de 1132 cP con una temperatura en pico de $89,9{ }^{\circ} \mathrm{C}$ y un tiempo en pico de $12,47 \mathrm{~min}$, la viscosidad máxima de la harina de plátano es relativamente baja, sin embargo, se presentaron valores por debajo de lo reportado por Lucas (2009) en harinas de diferentes variedades de plátano y por Dufour et al. (2009) con $1842 \mathrm{cp}$ en harina de plátano dominico hartón.

En la variable viscosidad de la pasta fría (VPF), la cual tiene que ver con la tendencia o habilidad de las suspensiones para formar una pasta viscosa o gel después de cocción o enfriamiento, la variedad dominico hartón presentó una viscosidad de 1221 cP.

Tabla 2. Propiedades de empastamiento de la harina y del almidón de plátano.

\begin{tabular}{lcc}
\hline Parámetros & Harina & Almidón \\
\hline Temperatura de inicio de gelatinización $\left({ }^{\circ} \mathbf{C}\right)$ & $75,11 \pm 0,55$ & $76,83 \pm 0,62$ \\
Tiempo en temperatura de inicio de gelatinización $(\mathbf{m i n})$ & $4,17 \pm 0,35$ & $5,5 \pm 0,3$ \\
Viscosidad máxima (cP) & $1132 \pm 52$ & $2068 \pm 102$ \\
Temperatura en pico $\left({ }^{\circ} \mathbf{C}\right)$ & $89,95 \pm 1,05$ & $89,95 \pm 0,55$ \\
Tiempo en pico (min) & $12,47 \pm 0,45$ & $8,6 \pm 0,2$ \\
Viscosidad mínima (cP) & $1114 \pm 63$ & $1783 \pm 84$ \\
Viscosidad de la pasta fría (VPF) (cP) & $1221 \pm 87$ & $2530 \pm 59$ \\
Breakdown (cP) & $18 \pm 3$ & $285 \pm 24$ \\
Setback (cP) & $107 \pm 12$ & $747 \pm 38$ \\
Facilidad de cocción $(\mathbf{m i n})$ & $8,03 \pm 0,21$ & $3,1 \pm 0,2$ \\
\hline
\end{tabular}


La variable Inestabilidad del gel (Breakdown), es un indicativo de que tan estables y resistentes al cizallamiento son los geles en procesos agroindustriales y representa la fragmentación de los gránulos. Para la harina de variedad dominico hartón la inestabilidad fue de 18 cP (entre menor sea la diferencia entre la viscosidad máxima y la viscosidad mínima, más estables son las harinas a la fragmentación mecánica).

En la variable reorganización (Setback), que define la reasociación de los polímeros de almidón solubles y los fragmentos granulares insolubles durante la fase de enfriamiento, se asocia a la retrogradación. Los valores registrados en la harina de plátano fue de 117 cP este valor estuvo por debajo de lo reportado por otros autores 456,07 cP (Lucas et al. 2010).

La facilidad de cocción en la harina fue de 8,3 min, valor alto comparado con lo reportado en otros estudios para harinas Doufor et al. (2009).

De acuerdo, a los bajos valores obtenidos en las variables, estabilidad a la fragmentación mecánica y su resistencia a la retrogradación y consistencia, las harinas de plátano dominico hartón podrían ser evaluadas en la elaboración de productos como harinas compuestas, alimentos enlatados, alimentos para niños, salsas, productos de panificación, jaleas, caramelos y embutidos cárnicos; también podrían ser usados en la elaboración de productos que requieran de altas temperaturas para su procesamiento.

Almidón. En las variables temperatura de inicio de gelatinización y tiempo en temperatura de inicio de gelatinización (Tabla 2), el almidón registró valores de $76,83{ }^{\circ} \mathrm{C}$ y 5,5 min respectivamente, valores que concuerdan por lo reportado (Lucas et al. 2010) en diferentes variedades de plátano. Estos valores son relativamente altos al necesitarse temperaturas más altas y mayores tiempos para que se inicie el proceso de gelatinización de los almidones, por lo cual es mayor el consumo de energía para que los gránulos de almidón se comiencen a hinchar.

El almidón desarrolló una viscosidad máxima de 2068 cP, variable que obtuvo un valor mayor que lo reportado en otros trabajos con $1695 \mathrm{CP}$ (Lucas et al. 2009), para diferentes variedades de plátano. El tiempo en pico y temperatura obtenidos fueron de $8,6 \mathrm{~min}$ y $89,9{ }^{\circ} \mathrm{C}$, estos últimos datos son similares a los obtenidos por Lucas et al. (2009), quienes reportaron valores de $89,9^{\circ} \mathrm{C}$ y $8,9 \mathrm{~min}$.

El almidón de plátano dominico hartón gelatiniza a temperaturas más altas que el almidón de maíz, papa y de yuca $\left(62-73{ }^{\circ} \mathrm{C}\right)$; (Linde boom et al. 2004); (Taggar 2004); (Alvis et al. 2008) pero está por debajo de las temperaturas de gelatinización de cereales con 74-81 ${ }^{\circ} \mathrm{C}$ (Taggart 2004).

Durante la fase de enfriamiento, se presentó un incremento en la viscosidad, la cual fue de 2530 cP, debido a la reorganización de las cadenas solubilizadas durante la fase de calentamiento y fase de sostenimiento, produciendo una red que retiene una mayor cantidad de moléculas de agua (Mali et al. 2003); (Gimeno et al. 2004) y dan las características de una pasta.

La inestabilidad del gel (Breakdown), obtuvo 
un valor de 285 cP, (entre menor sea la diferencia entre la viscosidad máxima y la viscosidad mínima, más estables son los almidones a la fragmentación mecánica. Lo anterior concuerda con Espinosa (2009), quien reportó un Breakdonwn de 335 cP.

Los valores de viscosidad de recuperación (Setback), se encuentran asociados a los contenidos de amilosa (Thitripraphunkul et al. 2003). Almidones con altos contenido de amilosa presentan mayores viscosidades de recuperación y se asocia a la retrogradación.

El almidón de plátano presentó valores de 747cP el cual es considerado alto. Espinosa, (2009), reportó un valor de 1417 cP en la variable setback para almidón de plátano, lo anterior concuerda con la tendencia que tiene el almidón de plátano a sufrir alta retrogradación. Las cualidades de retrogradación de los almidones, permiten usarlos como gelificantes en diversos productos, principalmente del sector alimenticio.

La variable facilidad de cocción se encuentra relacionada con el tiempo que transcurre en alcanzar el hinchamiento de todos los gránulos, desde el momento en que este se inicia. El almidón de plátano presentó un tiempo de 3 min. Los valores registrados se encuentran de acuerdo con lo reportado por (Lucas 2009), para diferentes variedades de plátano las cuales varían entre 2,0 y 3,5 min. Comparando la facilidad de cocción de plátano con almidón de yuca no se encuentran diferencias.

\section{CONCLUSIONES}

La evaluación térmica tanto de las harinas como del almidón, presentó características térmicas atractivas para reducción de costos energéticos en diferentes procesos agroindustriales. La viscosidad máxima de la harina es considerada baja y la facilidad de cocción es alta con un tiempo de 6,9 min; aunque la harina de plátano presentó baja retrogradación y alta estabilidad al cizallamiento. La harina de plátano puede ser estudiada en la producción de harinas compuestas trigo-plátano, podría ser utilizado en panificación, ya que retardaría el endurecimiento de los productos y se mantendrían suaves por más tiempo. Este comportamiento de la harina de plátano lo hace tecnológicamente inapropiado como sustituto en procesos que requieren retrogradación.

El almidón de plátano gelatiniza a una temperatura relativamente baja $76,8{ }^{\circ} \mathrm{C}$, el pico máximo es alcanzado rápidamente, lo que implica que es un almidón fácil de cocinar y requiere menor consumo de energía durante su cocción. Esto se puede evidenciar en el gasto de energía reportado en el DSC para almidón y en la variable facilidad de cocción la cual fue de 3 min. El almidón de plátano genera alta viscosidad (2068cP) y también genera alta retrogradación. La viscosidad máxima que genera el almidón es alta, podría tenerse en cuenta como ingrediente en sopas, cremas, base para salsas deshidratadas; pero la alta retrogradación que genera resulta inapropiada para estos productos por que se produce la recristalización, donde los cristales empiezan a formarse acompañados de un aumento gradual de la rigidez y de una sinéresis en la fase de separación entre el polímero y el disolvente.

La forma y el tamaño de los gránulos de almidón de plátano favorecen la formación del gel, esto es debido a que los gránulos de almidón 
encontrados mediante microscopia electrónica de barrido con tamaños promedios entre $7 \mu \mathrm{m}$ $53 \mu \mathrm{m}$ de longitud tiene mayor capacidad de absorción de agua, mayor velocidad de hidratación y se desintegran más rápidamente. Con las características evidenciadas en el presente trabajo, el almidón de plátano resulta interesante para evaluar su comportamiento en procesos de congelación y descongelación en la industria de helados y postres y el arreglo cristalino que mostró el almidón de plátano tipo C podría ser considerada una característica interesante para evaluarla en la producción de almidón resistente.

\section{REFERENCIAS}

Alfaro, Y., Segovia, V., Mireles, M., Monasterios, P., Alejos, G. y Pérez, M. 2008. El maíz amarillo para molienda húmeda. Revista Digital del Centro Nacional de Investigaciones Agropecuarias de Venezuela. CENIAP 6.

\section{Alkarkhi, A., Ramli, S., Yong, Y. and Easa, A.} 2011. Comparing physicochemical properties of banana pulp and peel flours prepared from green and ripe fruits, Food Chemistry 129(2): 312-318.

Alvis, A., Vélez, A., Villada, H. y Rada, M. 2008. Análisis físicoquímico, morfológico de almidones de Ñame, Yuca y Papa y determinación de la viscosidad de las pastas. Información Tecnológica 19(1):1928.

Amaga, E. 2005. Aislamiento y caracterización del almidón de maíces pigmentados. Agrociencia 39(004):425.
AOAC, Official methods of analysis. 2005. 17th Ed. Methods 925.10, 65.17, 923.03, 960.52, 922.06, 985.29, 991.42. . The Association of Official Analytical Chemists, Gaithersburg, MD, USA.

Aparicio, A. 2007. Obtención de almidón resistente por tratamiento de autoclave a partir de almidón de plátano modificado: Caracterización fisicoquímica, morfológica y estructural (Tesis). Instituto Politécnico Nacional de Desarrollo de Productos Bióticos. 117p.

Bakry, F., Carreel, F., Jenny, C. and Horry, J. 2008. Genetic Improvement of Banana, Chapter I. In Breeding Plantation Tree Crops: Tropical Species; Jain, S. M., Priyadarshan, P. M., Eds.; Springer: Dordrecht, The Netherlands, p3-50.

Bello, L., Panó, Y., Agama, E., and Paredes, O. 1998. Isolation and partial characterization of amaranth and banana starches. Starch/ Stärke 50:409-413.

Bello, L., Agama, E., Sayag, S., and Moreno, E. 2000. Some structural, physicochemical and functional studies of banana isolated from two varieties growing in Guerrero, Mexico. Starch/starker 52:68-73.

Bugaud, C., Chillet, M., Beauté, M., and Dubois, C. 2006. Physicochemical analysis of mountain bananas from the French West Indies. Scientia Horticulturae 108:167172.

Cardona, M., Sorza, J., Posada, S., Carmona, J., Ayala, S. y Álvarez, O. 2001. Establecimiento de una base de datos para la elaboración de tablas de 
contenido nutricional de alimentos para animales. Facultad de Ciencias Agrarias, Universidad de Antioquia. $3 p$.

Cooke, D. and Gidley, M. 1992. Loss of crystalline and molecular order during starch gelatinisation: origin of the enthalpic transition. Carbohydr Res, 227: 103-112.

Da Mota R., Lajolo F., Ciacco C. and Cordenunsi B. 2000. Composition and Functional Properties of Banana Flour from Different Varieties. En: Starch/Stärke 52(2-3):63-68.

Dufour, D., Gibert, O., Giraldo, A., Sánchez, T., Reynes, M., Pain, J., González, A., Fernández, A. and Díaz, A. 2009. Differentiation between cooking bananas and dessert bananas. 2. Thermal and functional characterization of cultivated Colombian Musaceae (Musa sp.). J. Agric. Food Chem 57(17):7870 - 7876.

Espinosa, V. 2008. Estudios estructurales de almidón de fuentes no convencionales: Mango (Manguifera Indica L), Plátano (Musa Paradisiaca L) (Tesis). Instituto Politécnico Nacional. Centro de Desarrollo de Productos Bióticos. Yuatepec, Morelos. p85.

Faisant, N., Gallant, D. J., Bouchet, B., and Champ, M. 1995. Banana starch breakdown in the human small intestine studied by electron microscopy. Eur. J. of clinical Nutr 49:98-104.

Flores, E. 2004. Rendimiento del proceso de extracción de almidón a partir de frutos de plátano (Musa paradisiaca). Estudio en planta piloto. Acta científica Venezolana 55(1):86-90.

García, Y., Zamudio, P., Bello, L., Romero, C. , y Solorza, J. 2011. Oxidación Del Almidón Nativo De Plátano Para Su Uso Potencial En La Fabricación De Materiales De Empaque Biodegradables: Caracterización Física, Química, Térmica Y Morfológica. Revista Iberoamericana de Polímeros: 12(3):135.

Gimeno, E., Moraru, C. and Kokini, J. 2004. Effect of xanthan gum and CMC on the structure and texture of corn flour pallets expanded by microwave heating. Cereal Chemistry 81:100-107.

Guilbot, A. and Mercier, C. 1985. Starch. In: The polysaccharides, (ED) O. Aspinall. Academic press, New York. p209-282.

Hurtado, J. 1997. Valorización de las amiláceas "no-cereales" cultivadas en los países andinos: Estudio de las propiedades fisicoquímicas y funcionales de sus almidones y de la resistencia a diferentes tratamiento estresantes (Tesis). Fundación Universidad de Bogotá Jorge Tadeo Lozano. Bogotá-Colombia. 164p.

Instituto Colombiano de Normas Técnicas y Certificación. ICONTEC. NTC 267. Harina de trigo 2007.

Juarez, E., Agama, E., Sayago, S., Rodriguez, S. and Bello, L. 2006. Composition, digestibility and application in breadmaking of banana flour. Plant Foods for Human Nutrition 61:131-137. 
Lassoudière, A. 2007. Le bananier et sa culture. France: Editions QUAE.

Lucas, J., Díaz, A. y Dufour, D. 2010. Caracterización físico-química y evaluación de las curvas deempastamiento de tres variedades de plátano: Hartón (Musa AAB), Cubano Blanco (Musa AAB), Cachaco (Musa ABB). En: Memorias Reunión Internacional Acorbat, Medellín, Colombia 2010. 412p.

Mali, S., Ferrero, C., Redigonda, J., Belia, A. P., Grossmann, M. and Zaritzky, N. 2003. Influence of $\mathrm{pH}$ and hydrocolloids addition on yam (Discorea alata) starch pastes stability Lebensmittel. Wissenschaft techologie 36:475-481.

Mestres, C. 1996. Los estados físicos del almidón. En: Conferencia internacional sobre Almidón. Propiedades físicoquímicas, funcionales y nutricionales: Usos. (1 ${ }^{\text {a }}$ 8-10, mayo: Quito; Ecuador.) Memorias. Ecuador: Escuela Politécnica Nacional e Instituto de Investigación Tecnológica. p1-16.

Millán, C., Méndez, M., Otthenhof, M., Farhat, I. and Bello, L. 2005. Determination of the molecular and structural characteristics of Okenia, Mango and Banana starches. J. Agric. Food Chem 53:495-501.

Nwokocha, L. and Williams, P. 2009. Some properties of white and yellow plantain (Musa paradisiaca, Normalis) starches, Carbohydrate Polymers 76(1):133-138.

Olayide S., Olusegun O., Awokoya, K. and Ogunkunle, A. 2002. The lowsubstituted propylene oxide etherified plantain (Musa paradisiaca normalis) starch: Characterization and functional parameters. Carbohydrate Polymers 74(3):717-724.

Oliveira, J., Junior, A., Bassinello, P., Mainardi, J., Purgato, E. and Lajolo, F. 2006. Betaamylase expression and starch degradation during banana ripening. Postharvest Biology and Technology 40(1):41-47.

Osorio, P., Aguilar, A., Agama, E., Rendón, R., Tovar, J. and Bello, L. 2008. Composite durum wheat flour/plantain starch white salted noodles: proximal composition, starch digestibility, and indigestible fraction content. Cereal Chemistry 85(3):339-343.

Paredes, O., Schevenin, M., Hernández, D. and Carabez, A. 1989. Amareanth Starch Isolation and Partial Characterization. Starch/Starke 41 205-207.

Pelissari, F., Andrade, M., Amaral, P. and Menegalli, F. 2013. Comparative study on the properties of flour and starch films of plantain bananas (Musa paradisiaca), Food Hydrocolloids 30(2):681-690.

Pineda, S., Coral, C. y Rosales R. 2011. Estudio de las propiedades térmicas de harinas de maíz producidas por tratamiento térmicoalcalino. Ingeniería Y Ciencia 7(14):119125.

Pineda, P., Coral, D., Ramos, D., Rosales, A. and Rodríguez, M. 2011. Thermo-alkaline treatment. A process that changes the 
thermal properties of corn starch. Procedia Food Science 1:370-378.

Rivas, M., Méndez, M., Sánchez, M., Núñez, M. y Bello, L. 2008. Caracterización Morfológica, Molecular Y Fisicoquímica Del. Redalyc. Sistema de Información Científica. Red de Revistas Científicas de América Latina, el Caribe, España y Portugal. p487-497.

Rodríguez, S., Sandoval, A. y Fernández, Q. 2006. Evaluación de la retrogradación del almidón de harina de yuca precocida. Revista Colombiana de Química 36(1):1330.

Rojas, I., Gutiérrez, E., Palacios, A., Baños, L., Pons, J., Guzmán, S., Pineda, P. and Rodríguez, M. 2007. Study of structural and thermal changes in endosperm of quality protein maize during traditional nixtamalization process. Cereal Chem 84(4):304-312.

Slade, L. and Levine, H. 1988. Non-equilibrium melting of native granular starch. 1.Temperature location of the glass transition associated with the gelatinisation of A-type cereal starches. 8. Carbohydrate Polymers. p183-208.
Soto, V. S. 2010. Cuantificación de almidón total y de almidón resistente en harina de plátano verde (musa paradisíaca) y banana verde (musa cavendish). Universidad Mayor de San Simón, Facultad de Bioquímica y Farmacia, Cochabamba Bolivia. 2p.

Taggar, P. 2004. Starch as an ingredient: manufacture and applications. In: Eliasson, A - C. Starch in Food. Structure, function and applications. CRC. Boca raton. NY. USA. pp. 363-392. Cambrige, UK: Woodhead publishing.

Tester, R. and Morrison, W. 1999. Swelling and gelatinization of cereal starches. I. Effects of amylopectin, amylose, and lipids. Cereal Chem 67(6):551-557.

Tian, S., Rickard, J. and Blanshard, J. 1991. Physicochemical properties of sweet potato starch. J. Sci. Food Agri 57:459491.

Vansteelandt, J. and Delcour, J. 1999. Characterisation of starch from durum wheat (Triticum durum). Starch/Starke 51: 73-80.

Whistler, R., and Be Miller, J. 1997. Carbohydrate Chemistry for Food Scientists. 1997. Gagan Press. St. Paul, Minnesota. 241p.

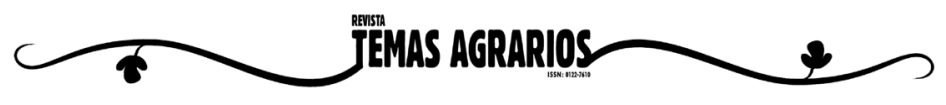

